requests allow the task to schedule other tasks for execution, one allows first-in, first-out queues to be set up, and most of the remainder are concerned with input or output. This last class of routines services interrupts and queues output, freeing the user from the need to worry about such commonly used peripheral devices as the Teletype, disk, magnetic tape, and video displays. These routines are relatively straightforward and will not be discussed further.

The control of all external devices is handled through the use of the interrupt system, never through flag-checking loops. The interrupt is turned on during most of the time when GASPS is in control. Program tasks may be executed with the interrupt either on or off, depending on the importance of the task and its length. When an interrupt takes place, control is passed to a service routine. Many of these routines are within GASPS itself; the remainder are user-written tasks.

A task may be executed at any of several priority levels. The priority of a task is specified when it is scheduled and determines when it will be executed. There are four levels of priority, with Priority Level 0 tasks executed first and Priority Level 3 tasks last. Within a priority level, the oldest requests are serviced first. The usage of the priority levels is as follows: Level 0 -These tasks service interrupts from external devices and take control after time delays. They are never interruptable. Level 0 tasks should be short, generally doing no more than a few simple $I / O$ requests and scheduling a new task. Level 1-Tasks requested at this level are executed immediately following the Level 0 tasks. Level 1 tasks are usually noninterruptable and should be used for short control operations. Level 2-These are used for longer and less urgent tasks, usually run with the interrupt on. Level 3-These are the lowest priority tasks and would be used for the largest tasks. With a small system, such as the $4 \mathrm{~K}$ PDP- 8 , there appears to be little use for this priority level. When a task is interrupted, processing will be resumed only after the interrupt and any higher priority tasks have been serviced.

An important part of the GASPS system is the timer. GASPS maintains a record of the time since its initialization, making use, in part, of the external hardware clock. A task can obtain this time and can also request that another task be executed after a given time interval. At the end of the interval, control is passed to the new task. Because these tasks service timer interrupts, they have Priority Level 0.
The basic GASPS system limits the user to approximately $2 \mathrm{~K}$ of program space. This is sufficient for quite complicated programs but, in some cases, can be limiting. The current version of GASPS allows tasks to be resident on the disk as well as in core. When scheduled, these tasks are brought into unused pages in core and executed at Priority Level 2 . The page system of addressing in the PDP-8 means that single-page tasks are page-wise relocatable, so that the eventual location of disk-resident tasks in core is not important. For this reason, these tasks are limited to one page (128 instructions) in length.

At this time, tasks for use with GASPS must be coded in PDP-8 Assembly language (PAL). This makes the programming somewhat slower than with a higher-level language, although, since GASPS tasks are short single-purpose routines, they are usually easy to code. The logic of the program is usually coutained in the interrelation of the tasks, not in their content, and it is possible to develop a library of tasks that can be combined with little modification to form new programs.

\title{
The PLANIT computer-assisted instructional language: A potential tool of research
} in psychology

\author{
M. A. RAHIMI and T. A. FINO \\ Department of Computer Science, Michigan State University \\ East Lansing, Michigan $\mathbf{4 8 8 2 2}$
}

The purpose of this presentation is to acquaint psychologists with an existing programming language which is easily obtainable and which may be used for collecting data and administering tests to human Ss in a great number of situations.

The programming language to be discussed is PLANIT (Programming Language for Interactive Teaching), which was developed by the System Development Corporation under contract from the National Science Foundation. This system was recently installed at Michigan State University, and it is expected that it will be installed in more than a dozen universities and research centers by June.
The language is designed for writing programs for presentation of textual information to students and the reading and recording of their responses. The logic used by an author in his program can make use of the student's response, together with information stored on his past performance, to determine the next step in presentation of instructional material.

A program written in PLANIT is a set of instructions for directing the interaction between man and machine at a computer terminal. The recording of the interaction is done automatically. The PLANIT program can be punched on cards and loaded into the computer, or it can be

Example 1. Interactive preparation of a PLANIT program.

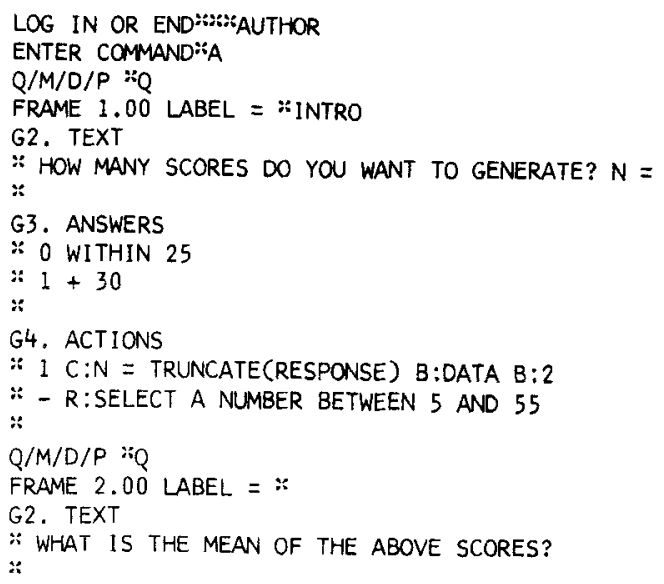


developed interactively. The interactive development means that the author can sit at a terminal and be prompted to provide the proper

G3. ANSWERS

* 0 RONO(4)

* 0 WITHIN . 1

$\because 1+$ MEAN

* 2 SUMS

G4. ACTIONS

$\because 1 \mathrm{~F}$ :

* 2 R: YOU FORGOT TO DIVIDE BY THE NUMBER OF OBSERVATIONS, $N$

$\because$ - R:HINT - ADD THE SCORES AND DIVIDE BY $N$ (USE CALC IF NECESSARY)

$\because-F$ :

$Q / M / D / P * Q$

FRAME 3.00 LABEL $=*$

G2. TEXT

* WHAT IS THE RELATIONSHIP BETWEEN YOUR SELECTED

* SCORES AND THE fOLLOWING NUMBER?

G3. ANSWERS

$\ddot{*}$

G4. ACTIONS

* C: PRINT STDEV

$\because$

Q/M/D/P :Q

FRAME 4.00 LABEL $=*$

G2. TEXT

$\because$ ENTER YOUR ANSWER ON ONE LINE OR LESS

G3. ANSWERS

$\because$ O KEYWORD ON

$\because$ O PHONETIC ON

$\because$ a + STANDARD DEVIATIION

* B + STD DEV

* C VARIANCE

$\because$

G4. ACTIONS

$\because A B F: B: G O O D$

* C R: NO, BUT IT'S THE SQUARE ROOT OF THAT. TRY AGAIN.

$\because-R:$

$\because$ - R: IT IS THE SQUARE ROOT OF THE VARIANCE. TRY AGAIN.

* - C: PRINT STDEV; "WAS THE STANDARD DEVIATION OF YOUR SCORES" B: REMEDIAL

$Q / M / D / P$ :P

FRAME 5.00 LABEL = "DATA

G2. STATEMENTS

* SET MATRIX (SCORES, N)

* SET STDEV = TRUNCATE (RANDOM::30)

"SCORES $(K)=$ NORMAL*STDEV + 100 FOR $(K=1, N)$

* ROUND (O)

$\because$ F: YOUR SELECTED SCORES ARE:

"ALIGN K, 5; "-" 5; SCORES (K), 10 FOR $(K=1, N)$

* SET SUMS = SUM SCORES $(K)$ FOR $(K=1, N)$

$*$ SET MEAN $=$ SUMS $/ N$

$\because$ RETURN

$x$

The author of this lesson makes use of a number of built-in functions of PLANIT. Some of these functions are:

WITHIN-Checks the S's numeric response within a given range.

ROUND-Rounds the numeric values computed by PLANIT.

KEYWORD-Checks for key words in S's response.

PHONETIC-Accepts phonetically equivalent responses that match the anticipated answer.

RANDOM-Generates a random number in the range 0.00 to 1.0 .

NORMAL-Generates a number with a mean of 0 and a standard derivation of 1.

SUM-Computes the sum of $\mathrm{N}$ numbers. information for correct development of the program. At any time during the development of a program, the author can execute the program, check for its correct behavior, and edit and change the program as required.

The usual terminal used for PLANIT is the Teletype or Teletype-compatible CRT (cathode-ray tube). This is determined by financial rather than technical consideration. In fact, we are experimenting with a small computer with a graphics terminal which should allow for many forms of nontextual interaction. For example, it is technically a simple matter to measure the involuntary responses of a $S$ (such as his heart rate) and have the computer record and use that information instantly to determine the next stimulus to be presented to the $S$.

There are a number of reasons why this system should be seriously considered by psychologists and others interested in interactive computing or man-machine interaction: (1) The system is designed to be installed on any computer that has an interactive computing capability (Geiger, McLane, Aaronson, \& Frye, 1970; Geiger, Aaronson, \& Frye, 1970a). (2) It is an easy language to learn and use. Individuals without any knowledge of computing can learn to make effective use of it within a few hours (Bennick \& Frye, $1970 a, b$ ). (3) Extension and modification of the system is relatively simple, since it is written in FORTRAN and extensive documentation is available (Geiger, Aaronson, \& Frei, 1970b). (4) Programs written in PLANIT at one installation will be transferable to another installation (PLANIT Newsletter, 1971). (5) A highly powerful computational language is available to the authors and users of PLANIT programs. This makes many standard mathematical or statistical calculations very trivial to use.

A program in PLANIT consists of a collection of frames. Each frame is identified by a number and a name. The number is assigned to the frame automatically, and the name is optional and can be assigned by the author. Four types of frames are available. They are: (1) question (Q) frames, which allow for presentation of a text to the $S$, the reading of his response, and the performance of a set of actions; these actions may be: presentation of a feedback message, repeating the question, or branching to another point in the program; (2) multiple-choice (M) frames, which are similar to $Q$ frames, except that 
Example 2. Interactive use of program written in Example 1.

LOG IN OR ENDESECESTUDENT

ENTER COMMAND" GET PSYSTAT

IDENTIFY YOURSELF::E:XJOE

HOW MANY SCORES DO YOU WANT TO GENERATE? $N=$ \# 98

SELECT A NUMBER BETWEEN 5 AND 55

* 8

YOUR SELECTED SCORES ARE:

$$
\begin{array}{r}
1-102 \\
2-97 \\
3-100 \\
4-100 \\
5-98 \\
6-101 \\
7-100 \\
8-102
\end{array}
$$

WHAT IS THE MEAN OF THE ABOVE SCORES?

$\because 100$

FINE

WHAT IS THE RELATIONSHIP BETWEEN YOUR SELECTEO

SCORES AND THE FOLLOWING NMMBER?

2.0

ENTER YOUR ANSWER ON ONE LINE OR LESS

* I DON'T KNOW

WRONG, TRY AGAIN

"I REALLY DON'T KNOW

IT IS THE SQUARE ROOT OF THE VARIANCE. TRY AGAIN. ־PLEASE TELL ME

2.0 WAS THE STANDARD DEVIATION OF YOUR SCORES

the answer must be selected from a list provided by the author; (3) decision (D) frames, which allow the examination of the data recorded for the $S$; and (4) programming (P) frames, which are used as a subroutine for computation.

The PLANIT system, as shown in the examples, prints one or more lines or messages and then prints an asterisk at the beginning of a line and waits for the response of the author of the program or the $S$.

To learn more about PLANIT, the publications referenced should be consulted. Information can also be obtained about PLANIT by dialing our computer in East Lansing from any telephone in the U.S. or Canada and requesting the execution of a set of tutorial lessons we have developed for

Example 3. Another interactive use of program written in Example 1.

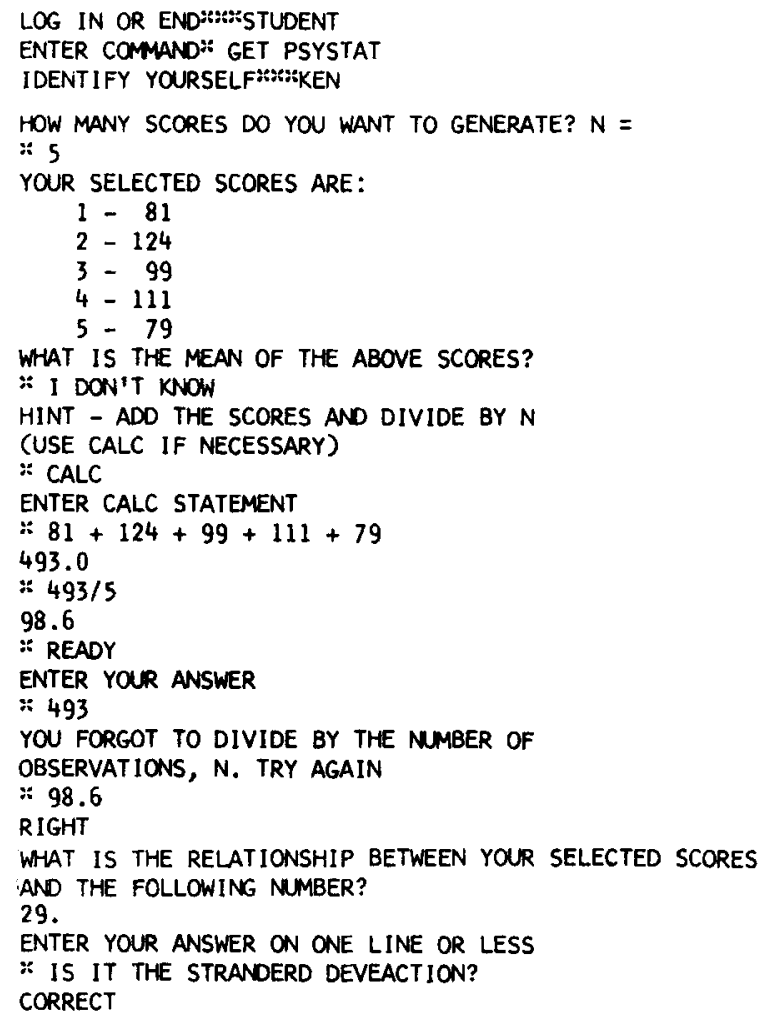

In this example, misspellings by the $S$ (the line before last) is correctly interpreted, since the PHONETIC function was turned on by the author (Example 1, Frame 4, under G3).

teaching PLANIT-a case of PLANIT teaching PLANIT.

\section{REFERENCES}

BENNICK, F. D., \& FRYE, C. H. PLANIT author's guide. SDC Technical Memorandum TM-(L)-4422/001/01, $1970 \mathrm{a}$.

BENNICK, F. D., \& FRYE, C. H. PLANIT language reference manual. SDC Technical M e morandum TM-(L)-4422/002/01, $1970 \mathrm{~b}$.

GEIGER, E. R., McLANE, D. G. AARONSON, D. C., \& FRYE, C. H. ICÜ
System installation manual. SDC Technical M e morandu m TM-(L)-4422/004/00, 1970.

GEIGER, E. R., AARONSON, D. C., \& FRYE, $\dot{\text { C. }}$ H. ICU/PLANIT System program generator. SDC Technical Memorandum TM-(L)-4422/007/00, 1970 .

GEIGER, E. R., AARONSON, D. C., \& FRYE, C. H. ICU System program description. SDC Technical Memorandum TM-(L)-4422/003/00.

PLANIT Newsletter. PLANIT User's Group, Department of Computer Science, Michigan State University, Vol. 1, No. 1, December 1971 